\section{Antioxidant activity and possible bioactive components in hydrophilic and lipophilic fractions from the seaweed Halimeda incrassata}

\author{
Alexis Vidal Novoa, ${ }^{1}$ Elma R. S. Andrade-Wartha, ${ }^{2}$ Adyary \\ Fallarero Linares, ${ }^{3}$ Ana Mara de O. e Silva, Maria Inês \\ Genovese, ${ }^{2}$ Ana Elsa B. González, ${ }^{1}$ Pia Vuorela, ${ }^{3}$ Ariadna Costa, ${ }^{1}$ \\ Jorge Mancini-Filho ${ }^{* 2}$
}

${ }^{1}$ Faculdad de Biología, Universidad de la Habana, Cuba,

${ }^{2}$ Departmento de Alimentos e Nutrição Experimental, Faculdade de Ciências Farmacêuticas, Universidade de São Paulo, Brazil,

${ }^{3}$ Division of Pharmacy, Department of Biochemistry and Pharmacy, Faculty of Mathematics and Natural Sciences, Abo Akademi University, Turku, Finland.

\begin{abstract}
Hydrophilic and lipophilic fractions, obtained from the marine algae Halimeda incrassata (J.Ellis) J.V.Lamouroux, Halimedaceae, were studied by using the $\beta$-carotene-linoleate assay system. In case of hydrophilic fractions, the total phenolic compounds were quantified and two of their components were identified as salicylic and ferulic acids. From the lipophilic fraction, fatty acid composition was studied. The highest antioxidant activities values were found on the polar fractions containing phenolic acids. The total phenolics content on the hydrophilic fractions was $255 \mu \mathrm{g}$ of gallic acid equivalents/g of fresh seaweed. To further characterize H. incrassata chemical composition, the total lipid content was quantified ( $7.4 \mathrm{mg}$ per gram of dried algae) as well as the saturated and unsaturated fatty acids ratio (1:1.46). In summary, this paper adds more convincing evidences in support of the antioxidant abilities of the lyophilized aqueous extract of Halimeda incrassata and it also relates this bioactivity, for the first time, with particular phenolic components of the extract. Altogether, these results represent another step towards the use of this natural product as drug candidates.
\end{abstract}

Revista Brasileira de Farmacognosia Brazilian Journal of Pharmacognosy 21(1): 53-57, Jan./Feb. 2011

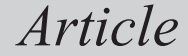

Received 11 Sep 2009

Accepted 16 Jul 2010 Available online 4 Feb 2011

Keywords: seaweed natural antioxidants Halimeda incrassate polyphenols fatty acids

ISSN 0102-695X doi: $10.1590 / \mathrm{S} 0102-695 \mathrm{X} 2011005000010$

\section{Introduction}

In the last ten years, the interest on the study of seaweeds as sources of bioactive compounds has increased. Such tendency could be at least partially explained on the basis of their chemical components, which exhibit different beneficial properties for the human health (Shin et al., 2006).

It is well known that algae contain minerals, polysaccharides, amino acid derivatives, carotenoids and phenolic compounds. These can display antioxidant properties at very low concentrations, which has been exploited on the food industry to protect foods from oxidation process (Yuan \& Walsh, 2006). In addition, epidemiological research has supported the existence of an inverse correlation between the incidence of cardiovascular diseases and consumption of phenolicrich foods (Bocanegra et al.,2009).

Different seaweed extracts have received increased attention, due to their potent pharmacological effects, particularly in vivo hypolipidemic (Ara et al., 2002) antioxidant (Yuan \& Walsh, 2006), immunological (Saker et al., 2004) and antitumoral activities (Lee \& Sung, 2003). Similarly, in vitro studies have confirmed the antioxidant properties of seaweed extracts (Nakai et al., 2006) which has suggested their possible uses as nutraceuticals and/or phytodrugs.

Some groups have studied the ability of seaweed extracts to inhibit lipid peroxidation or to scavenge free radicals (Fayaz et al., 2005; Dutra et al., 2007). Different compounds such as carotenoids, mycosporine-related amminoacids and terpenoids together with phenolic compounds as cinnamic acids, phlorotannins, and bromophenols has been identified among the principal entities responsible for these properties in marine algae (Shick \& Dunlap, 2002; Fisch et al., 2003).

The green seaweed Halimeda incrassata (J.Ellis) J.V.Lamouroux, Halimedaceae, is a specie that grows in shallow waters, and thus it is exposed 
to a combination of light and oxygen that leads to the formation of free radicals. However, the absence of oxidative damage on the structural components of seaweeds and their stability to oxidation during storage indicate that their cells should have protective antioxidative defense systems. Halimeda incrassata aqueous extract has been investigated over the past years by our group as a source of natural antioxidants and neuroprotectant compounds. Indeed, several lines of results have documented the ability of this natural product to target free-radical mediated processes on in vitro and in vivo experimental models (Rivero et al., 2003; Linares et al., 2004; Vidal et al., 2009). However, in spite of previous efforts, important information is still lacking in relation to: i) the polar components of this aqueous extract underlying its antioxidant and neuroprotective properties and ii) the antioxidant properties of non-polar fractions obtained from Halimeda incrassata and its possible bioactive components.

Thus, in view of these previous considerations, the aim of this study was to evaluate the antioxidant capacity of the hydrophilic and lipophilic fractions obtained from the green seaweed Halimeda incrassata, and to identify and quantified the metabolites contained on such fractions.

\section{Materials and Methods}

\section{Seaweeds collection}

The seaweed specie (Halimeda incrassata (J.Ellis) J.V.Lamouroux, Halimedaceae) was collected on August (2008), in the area of Bajo de Santa Ana, Havana City west coast, Cuba. Specimens were authenticated by Dr. A.M. Suárez from Seaweeds Laboratory, at the Marine Research Center of the University of Havana, where a voucher CIM (Suárez) 1973 was also deposited.

\section{Hydrophilic fractions preparation}

Fractions containing phenolic acids either in free form or as soluble esters were obtained according to Vidal et al. (2009). Dry seaweed (1 g) was extracted six times with tetrahydrofuran (THF, $20 \mathrm{~mL}$ ) during $3 \mathrm{~min}$, and evaporated to dryness under vacuum at $30{ }^{\circ} \mathrm{C}$ and after resuspended in $5 \mathrm{~mL}$ of methanol; these extracts were analyzed for free phenolic acids (FPA). The remaining residue was extracted with methanol:acetone:water $(7: 7: 6)$ and then filtered. The obtained supernatant was hydrolyzed by adding $\mathrm{NaOH} 4 \mathrm{~N}$ and the solution was adjusted to $\mathrm{pH} 2$. The obtained phenolic acids were extracted with ethyl eter:ethylacetate:THF $(1: 1: 1)$. The organic phase was rotoevaporated and resuspended into methanol, this was analyzed for phenolic acids soluble esters (PASE).

\section{Determination of total phenol concentrations}

Total phenolics was determined as in Vidal et al. (2009) and expressed as $\mathrm{mg}$ of gallic acid/g of seaweed.

\section{Identification and quantification of phenolic compounds}

Phenolic and cinnamic acids were evaluated according to Vidal et al. (2009). Different seaweed fractions were analyzed by Gas Chromatography on a GC Shimadzu 17 A equipped with a FID and a DB-5 fused-silica capillary column (J \& W Scientific $5 \%$ fenil-methylpolisiloxane $(30 \mathrm{~m} \times 0,25 \mathrm{~mm} \times 0,25$ $\mu \mathrm{m})$. Helium was used as the carrier gas. Peak areas were computed by a GC Workstation Class-GC-10 (Shimadzu) integrator.

\section{Lipophilic fractions preparation}

The freshly collected specimens were washed with distilled water and dried at room temperature for several days. The dried seaweed were milled into powder and then sieved. Lipophilic fractions were obtained with methanol, and later with chloroform, then the solution was filtered. The remaining residue was mixed with chloroform: methanol $(3: 1)$ and $\mathrm{KCl}$ $0.88 \%$ was further added. Organic later was finally evaporated to dryness. The obtained fatty acids were methylated according to the procedure described by Hartman \& Lago (1973) using heptadecanoic acid as internal standard. The mixture of $\mathrm{NH}_{4} \mathrm{Cl}$ in methanol: $\mathrm{H}_{2} \mathrm{SO}_{4}$ was used as methylating agent. In all fractions, total solutes were quantified by gravimetric analysis.

\section{Identification and quantification of fatty acids}

Aliquots of methylated fatty acids obtained by the Halimeda incrassata were studied by Gas Chromatography according to AOAC method (Cunniff, 1995) using an GC Shimadzu 17 A equipped with a FID and a Supelcowax 10 fused-silica capillary column (Supelco $30 \mathrm{~m} \times 0,25 \mathrm{~mm} \times 0,25 \mu$, USA). Helium was used as the carrier gas. Peak areas were computed by a GC Workstation Class-GC-10 (Shimadzu) integrator.

Measurement of antioxidant activity with $\beta$-carotene/ linoleic acid assay

The antioxidant activity of the different fractions was evaluated according to Vidal et al. 
(2009), using a mixture of $\beta$-carotene and linoleic acid from Sigma ${ }^{\circledR}$. Initial absorbance at $470 \mathrm{~nm}$ was taken at zero time and the absorbance measurements were repeated at $15 \mathrm{~min}$ intervals during $120 \mathrm{~min}$. Butylated hydroxytoluene (BHT Sigma ${ }^{\circledR}$ ) was used as positive control.

\section{Statistical analysis}

All experiments were carried out by triplicate and results were expressed as mean value \pm standard deviation. In antioxidant activity measurements, the group's comparisons were performed by one-way Analysis of Variance (ANOVA) and Tukey post test. $p<0.05$ was always considered statistically significant.

\section{Results and Discussion}

Seaweeds have recently attracted much attention as a source of bioactive compounds due to, at least in part, to the growing body of epidemiological studies supporting the beneficial effects of seaweed consumption in a variety of pathological conditions.

Phenolic compounds represent a large and heterogeneous group of biologically active substances, widely occurring in vegetable products and seaweeds, with important roles on cell metabolism and physiology. Their biological activities, including antioxidant properties, have suggested their positive effects on the human health (Bravo, 1998).

The phenolic content measured on the hydrophilic fractions obtained from the seaweed Halimeda incrassata are shown in Table 1. Both fractions exhibits high value of total phenolic compounds, from which more than half $(63 \%)$ corresponds to free phenolic acids, while $37 \%$ represents PASE compounds. In the free phenolic acids fraction, about $32 \%$ was identified as salicylic acid, while a small fraction was associated to ferulic acid. In the PASE fraction, same compounds were identified, and salicylic acid was also found as an important component, representing $27 \%$ of the total PASE content.

Values of phenolic contents reported here for hydrophilic fractions of $H$. incrassata are higher than those referred for a variety of seaweeds, but

Table 1. Content of total phenolic compounds ( $\mu \mathrm{g}$ of phenolics $/ \mathrm{g}$ of fresh seaweeds), yield (\%) and phenolic acids identified on the fractions of free phenolic acids and soluble esters of phenolic acids obtained from the seaweed Halimeda incrassata.

\begin{tabular}{ccccc}
\hline Fraction & $\begin{array}{c}\text { Phenolic } \\
\text { compounds } \\
\mu \mathrm{g} / \mathrm{g}^{*}\end{array}$ & Yield $(\%)$ & $\begin{array}{c}\text { Salicylic acid } \\
(\mu \mathrm{g} / \mathrm{g} \text { of fresh } \\
\text { seaweed)* }\end{array}$ & $\begin{array}{c}\text { Ferulic acid } \\
(\mathrm{ng} / \mathrm{g} \text { of fresh } \\
\text { seaweed)* }\end{array}$ \\
\hline FPA & $160 \pm 15$ & 0.016 & $51 \pm 4$ & $7,5 \pm 0.2$ \\
PASE & $95 \pm 6$ & 0.0095 & $26 \pm 5$ & $8 \pm 0.2$ \\
\hline
\end{tabular}

*mean \pm standard deviation corresponds to the level found in Fucus vesiculosus and Bryothamnion triquetrum. A relation between phenolics content and reactive oxygen species (ROS) scavenging abilities was observed for the hydrophilic fractions of $H$. opuntia and $H$. monile and this finding is an agreement with previous reports made for edible seaweed extracts (Vidal et al., 2009)

The antioxidant activity of the polar fractions obtained from the seaweed Halimeda incrassata is shown in Figure 1. The different hydrophilic fractions from the extracts exhibit a high antioxidant activity. The result regarding the high antioxidant activity displayed by the hydrophilic fractions of $H$. incrassata is also in agreement with earlier reports. The polar fractions of $H$. incrassata may contain others bioactive compounds which to could be directly responsible for the antioxidant activity, as carotenoids and polysaccharides (Rivero et al., 2003; Linares et al., 2004).

Next step was directed towards the isolation of free and esterified phenolic acids fractions and two different phenolic acids: ferulic and salicylic acids were identified as bioactive components. Phenolic and cinnamic acids have been considered responsible for antioxidant properties of plants and algae extracts. Although ferulic acid levels are very low in $H$. incrassata, the free radicals scavenging properties of this cinnamic acid have been very well documented even at very low concentrations (Nardini et al., 1995). Salicylic acid is widely found on plants, and several lines of evidences support its involvement on the plant defense mechanisms against oxidative stress (Rao et al., 1997). Different authors and also our group have referred the presence of salicylic or ferulic acids in microalgae and macroalgae displaying antioxidant properties (Fallarero et al., 2006).

Apart from salicylic and ferulic acids, other phenolic compounds could be related to the antioxidant properties of $H$. incrassata. Some studies have indicated the presence of significant amounts of simple bromated polyphenolic compounds in Halimeda spp and have also

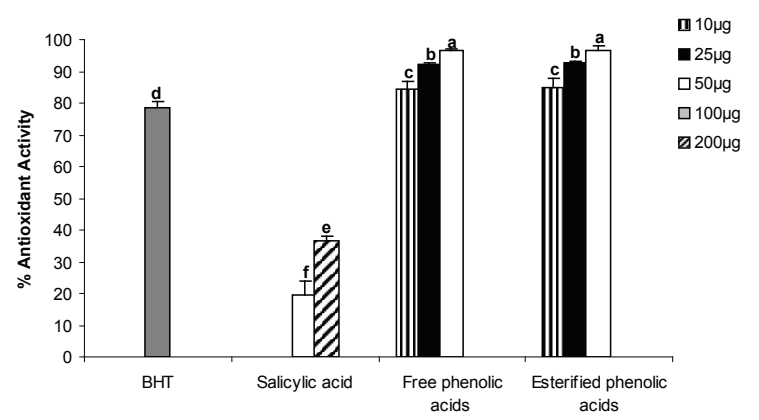

Figure 1. Antioxidant activity (referred to $\mu \mathrm{g}$ of phenolic compounds) measured on fractions containing free (FPA) and esterified phenolic acids (PASE) obtained from the seaweed Halimeda incrassata. Different letters means statistical differences $p<0.05$. 
identified and quantified different flavonoids and catechins in H. opuntia and H. macroloba (Yoshie et al., 2002).

The lipid content in $H$. incrassata was determined to be low $(7.4 \mathrm{mg}$ of lipid fraction $/ \mathrm{g}$ of dried algae). Fatty acid composition analysis (Table 2) demonstrates that saturated: unsaturated ratio in $H$. incrassata is high (1:1.46), considered as a significant nutritional feature for this algal product. Fatty acids have been traditionally regarded as "target" molecules on oxidative stress situations, and the formation of new lipid radicals during lipid peroxidation processes contributes to the oxidative damage and exacerbates free radical toxicity. However, authors have suggested that fatty acids may also exert antioxidant functions, in marine algae and natural products (Huang \& Wang, 2004)

Table 2. Fatty acid composition (mg of fatty acid/g of esterified lipids) of Halimeda incrassata.

\begin{tabular}{lcc}
\hline Fatty acid & Formulae & Content $(\mathrm{mg} / \mathrm{g})^{*}$ \\
\hline Tridecanoic & $\mathrm{C} 13: 0$ & $35.4 \pm 0.7$ \\
Myristic & $\mathrm{C} 14: 0$ & $18.6 \pm 0.6$ \\
Myristoleic & $\mathrm{C} 14: 1$ & $19.9 \pm 1.4$ \\
Palmitic & $\mathrm{C} 16: 0$ & $219.9 \pm 15.8$ \\
Estearic & $\mathrm{C} 18: 0$ & $22.1 \pm 0.8$ \\
Oleic & $\mathrm{C} 18: 1$ & $285.8 \pm 5.8$ \\
Eicosenoic & $\mathrm{C} 20: 1$ & $30.9 \pm 0.7$ \\
Eicosatrienoic & $\mathrm{C} 20: 3 \mathrm{n}-3$ & $58.3 \pm 1.2$ \\
Arachidonic & $\mathrm{C} 20: 4$ & $21.8 \pm 0.7$ \\
Docosapentaenoic & $\mathrm{C} 20: 5$ & $26.8 \pm 0.1$ \\
Lignoceric & $\mathrm{C} 24: 0$ & $23.6 \pm 2.3$ \\
Nervonic & $\mathrm{C} 24: 1$ & $22.1 \pm 0.4$ \\
\hline \multirow{2}{*}{ TOTAL } & Saturated & 319.6 \\
& Unsaturated & 465.6 \\
\hline
\end{tabular}

*mean \pm standard deviation

The lipophilic fractions obtained from $H$. incrassata exhibit antioxidant activity, although lower to the results registered for the hydrophilic fractions with values between 19.2 to $37.3 \%$ of antioxidant activity (data not shown).

The antioxidant activity of the lipophilic fractions could apparently be related to the content of unsaturated fatty acid, as in Huang \& Wang (2004), who have also found a direct relationship between antioxidant activity and unsaturated fatty acids content. In current research, antioxidant activity exerted by lipophilic fractions may occur during initiation reactions of lipid peroxidation, as a fatty acid could accept a free radical involved on the initiation of lipid peroxidation. Thus, the overall scenario indicates that fatty acids cannot be regarded as an efficient long-term defensive system against oxidative stress, combined to the profound metabolic disturbances that could be also implicated as result of lipid oxidative degradation (Aruoma, 2003).

In summary, the hydrophilic fractions obtained from the green seaweed Halimeda incrassata display a potent antioxidant activity as assessed by the $\beta$-carotenelinoleate assay, which could be at least partially explained by the presence of salicylic and ferulic acids, although the involvement of other phenolic compounds is not excluded. The fatty acid content on $H$. incrassata is low, but the content of unsaturated fatty acids is relatively high. Although the lipophilic fraction was shown to exert antioxidant activity, finally this fraction will act with pro-oxidant effect. Thus, current results support the notion that marine algae $H$. incrassata is a source of hydrophilic antioxidants, which could be further recommended for the prevention of oxidativestress related disturbances, and can be of usefulness either as dietetic supplements or as food ingredients.

\section{Acknowledgments}

We would like to express our gratitude to the financial support received from $\mathrm{CNPq}$, Project $\mathrm{PV} / 400001 / 2009$.

\section{References}

Ara J, Sultana V, Qasim R, Ahmad VU 2002. Hypolipidaemic activity of seaweed from Karachi Coast. Phytother Res 16: 479-483.

Aruoma OI 2003. Methodological considerations for characterizing potential antioxidant actions of bioactive components in plant foods. Mutat Res 523524: 9-20.

Bocanegra A, Bastida S, Benedi J, Rodenas, S SanchezMuniz FJ 2009. Characteristics and nutritional and cardiovascular-health properties of seaweeds. $J$ Med Food 12: 236-258.

Bravo L 1998 Polyphenols: Chemistry, dietary sources, metabolism, and nutritional significance. Nutr Rev 56: 317-333

Cunniff P 1995. Fatty acid in encapsulated fish oils and fish oil methyl and ethyl esters. Gas Chromatographic Method. In: AOAC Official methods of Analisis. 16. ed. Arlington: AOAC International. p. 20-22.

Dutra Rocha F, Crespo Pereira R, Coelho Kaplan MA, Laneuville Teixeira V 2007. Produtos naturais de algas marinhas e seu potencial antioxidante. Rev Bras Farmacogn 17: 631-639.

Fallarero A, Tammela P, Loikkanen J, Vidal A, Vuorela P 2006. Are cinnamic acids responsible for in vitro neuroprotection exerted by Bryothamnion triquetrum (S.G.Gmelin) Howe aqueous extract? Planta Med 72: 
191 (DOI: 10.1055/s-2006-949991).

Fayaz M, Namitha KK, Murthy KNC, Sarada R, Khanam S, Subbarao PV, Ravishankar GA 2005. Chemical composition, iron bioavailability, and antioxidant activity of Kappaphycus alvarezzi (Doty). J Agric Food Chem 53: 792-797.

Fisch KM, Böhm V, Wright AD, König GM 2003. Antioxidative meroterpenoids from the brown alga Cystoseira crinita. J Nat Prod 66: 968-975.

Hartman L, Lago RCA 1973. Rapid preparation of fatty acid methyl esters from lipids. Lab Pract 22: 475-477.

Huang HL, Wang BG 2004. Antioxidant capacity and lipophilic content of seaweeds collected from the Qingdao coastline. J Agric Food Chem 58: 49934997.

Lee EJ, Sung MK 2003. Chemoprevention of azoxymethaneinduced rat colon carcinogenesis by seatangle, a fiber-rich seaweed. Plant Foods Human Nutr 58: 1-8.

Linares AF, Loikkanen J, Jorge MF, Soria RB, Novoa AV 2004. Antioxidant and neuroprotective activity of the extract from the seaweed, Halimeda incrassata (Ellis) Lamouroux, against in vitro and in vivo toxicity induced by methyl-mercury. Vet Hum Toxicol 46: $1-5$.

Nakai M, Kageyama N, Nakahara K, Miki W 2006. Phlorotannins as radical scavengers from the extract of Sargassum ringgoldianum. Mar Biotechnol 8: 40914.

Nardini M, D’Aquino M, Tomassi G, Gentili V, Di Felipe M, Scaccini C 1995. Inhibition of human low-density lipoprotein oxidation by caffeic acid and other hydroxycinnamic acid derivatives. Free Radic Biol Med 19: 541-552.

Rao MV, Paliyath G, Ormrod P, Murr DP, Watkins CB 1997. Influence of salicylic acid on $\mathrm{H} 2 \mathrm{O} 2$ production, oxidative stress, and $\mathrm{H}_{2} \mathrm{O}_{2}$-metabolizing enzymes. Plant Physiol 115: 137-149.

Rivero F, Fallarero A, Castañeda O, Dajas F, Manta E, Areces A, Mancini J, Vidal A 2003. Antioxidant activity in vivo and in vitro of Halimeda incrassata aqueous extracts. Cienc Tecnol Aliment 23: 256-263.

Saker KE, Fike JH, Veit H, Ward DL 2004. Brown seaweed(Tasco) treated conserved forage enhances antioxidant status and immune function in heat-stressed wether lambs. J Anim Physiol Anim Nutr (Berl) 88: 122-130.

Shick JM, Dunlap WC 2002. Mycosporines-like amino acids and related gadusols: Biosynthesis, accumulation, and UV-protective functions in aquatic organisms. Annu Rev Physiol 64: 223-262.

Shin HC, Hwang HJ, Kang KJ, Lee BH 2006. An antioxidative and antiinflammatory agent for potential treatment of osteoarthritis from Ecklonia cava. Arch Pharm Res 29: 165-171.

Vidal A, Andrade-Wartha ERS, Silva AMO, Pavan R, Lima A,
Fallarero A 2009. Actividad antioxidante y polifenoles de las algas marinas Halimeda opuntia y Halimeda monile. Ars Pharm 50: 24-31.

Yoshie Y, Wang W, Hsieh Y P, Suzuki T 2002. Compositional difference of phenolic compounds between two seaweeds, Halimeda spp. J Tokyo Univ Fish 88: 2124.

Yuan YV, Walsh NA 2006. Antioxidant and antiproliferative activities of extracts from a variety of edible seaweeds. Food Chem Toxicol 44: 1144-1150.

\section{*Correspondence}

Jorge Mancini-Filho

Departmento de Alimentos e Nutrição Experimental, Faculdade de Ciências Farmacêuticas, Universidade de São Paulo, Brazil

jmancini@usp.br

Tel. +551130913674 